\title{
PERTUMBUHAN TANAMAN JATI UNGGUL NUSANTARA DENGAN POLA AGROFORESTRY UMUR LIMA TAHUN
}

\author{
Bambang Supriono* dan Luluk Setyaningsih \\ Staf Pengajar Universitas Nusa Bangsa \\ Jl. K. H. Sholeh Iskandar, Cimanggu, Tanah Sareal - Bogor 16166 \\ *email : basoe_53@yahoo.com
}

\begin{abstract}
\section{Growth of Superior Teak Plant Nusantara With Agroforestry Pattern at Five Years Old}

\begin{abstract}
Superior Teak Nusantara (JUN) is a product of Teak seedlings produced by Setyamitra Co vegetatively from "Perum Perhutani teak plus stands" and by inducing the root in order to raises the compound root. JUN has been planted in the Cogreg experimental garden, using the pattern of intercropping with annual crops and seasonal crops and currently JUN is 5 years old. This study was conducted to determine the effect of intercropping on the growth pattern of height, diameter and volume of JUN at 5 years old and looking for patterns of relationship between the volume and a diameter of JUN. Data were analyzed by linear regression and General Linear Model - Multivariate. Samples determined JUN tree with random start systematic sampling with a sampling intensity of $10 \%$. In the two plots of the intercropping management and one plot without intercropping met in which to be done observation of the branch height, total height and diameter at breast height of JUN. The results showed that intercropping patterns greatly affect the growth of Superior Teak Nusantara (JUN) of five years old (height, diameter and volume as well as the average annual increment of height, diameter and average annual increment of volume). Superate Teak Nusantara (JUN) Growth of average annual increment without in intercropping pattern of management (control) was greatest than both management, for diameter of $3.17 \mathrm{~cm} /$ year, for high was $2.66 \mathrm{~m} /$ year and the average annual increment for volume was 0,039 m3/year. Occured very close relationship between volume and diameter wath equation of $Y=1.063 \times 10-4 X$ 2,343. The results of the multivariate analysis, treatment variables (independent variables) affect the variable diameter, height and volume (dependent variable) Superior Teak Nusantara (JUN). The results of the analysis of the estimation of the diameter of the pattern of annual crop management has a diameter of $0.235 \mathrm{~cm}$ lower than the one with crop management patterns crop in turn.
\end{abstract}

Keywords : New Teak Seeds, Crop Intercropping, Teak Superior Archipelago (JUN)

\begin{abstract}
ABSTRAK
Jati Unggul Nusantara (JUN) adalah suatu produk semai Jati yang diproduksi oleh PT. Setyamitra secara vegetatif dari tegakan jati plus Perum Perhutani dan dengan menginduksi akarnya sehingga memunculkan akar tunggang majemuk. JUN telah ditanam di kebun percobaan Cogreg, dengan menggunakan pola tumpangsari dengan tanaman pertanian tahunan serta tanaman semusim dan saat ini JUN telah berumur 5 tahun. Penelitian ini dilakukan untuk mengetahui pengaruh pola tumpangsari terhadap pertumbuhan tinggi, diameter dan volume JUN umur 5 tahun, serta mencari pola hubungan antara volume dengan diameter JUN. Penelitian dianalisis dengan regresi linier dan General Linear Model-Multivariate. Sampel pohon JUN ditentukan secara systematic sampling with random start dengan intensitas sampling $10 \%$. Dalam dua petak pengelolaan pola tumpangsari dan satu petak tanpa tumpangsari yang di dalamnya dilakukan pengamatan terhadap tinggi bebas cabang dan tinggi total serta diameter setinggi dada JUN. Hasil penelitian menunjukkan bahwa pola tumpangsari sangat berpengaruh terhadap pertumbuhan Jati Unggul Nusantara (JUN) umur lima tahun (tinggi, diameter dan volume serta riap rata-rata tahunan untuk tinggi, diameter dan riap rata - rata tahunan volume). Pertumbuhan Jati Unggul Nusantara (JUN) riap rata - rata tahunan pada pola pengelolaan tanpa tumpangsari (kontrol) mempunyai riap rata-rata tahunan paling besar dibanding kedua pengelolaan, untuk diameter sebesar $3,17 \mathrm{~cm} / \mathrm{tahun}$, untuk tinggi sebesar 2,66 m/tahun dan riap rata - rata tahunan untuk volume sebesar $0,039 \mathrm{~m}^{3} /$ tahun. Terjadi hubungan yang sangat erat antara volume dan diameter dengan persamaan $\mathrm{Y}=1,063 \times 10^{-4} \mathrm{X}^{2,343}$. Hasil analisisi dengan multivariat, variabel perlakuan (variabel independen) berpengaruh terhadap variabel diameter tinggi dan volume (variabel dependen) Jati Unggul Nusantara (JUN). Hasil analisis estimasi terhadap diameter pada pola pengelolaan tanaman tahunan mempunyai diameter lebih rendah $0,235 \mathrm{~cm}$ dibandingkan dengan pola pengelolaan tanaman giliran.
\end{abstract}

Kata Kunci : Bibit Jati Baru, Tanaman Tumpangsari, Jati Unggul Nusantara (JUN) 


\section{PENDAHULUAN}

\section{Latar Belakang}

Sosial forestry adalah sistem pengelolaan sumberdaya hutan pada kawasan hutan Negara atau hutan hak, yang memberi kesempatan kepada masyarakat setempat sebagai pelaku atau mitra utama dalam rangka meningkatkan kesejahteraannya dan mewujudkan kelestarian hutan (Permenhut P.01/Menhut-II/2004) dalam Winarto, B (2006).

Pengembangan kegiatan penanaman hutan yang telah diterapkan di Indonesia menggunakan berbagai pendekatan, salah satunya adalah perhutanan sosial, dimana pendekatan ini menyertakan masyarakat sebagai salah satu stake holder penting dalam seluruh aspek pengelolaannya.

Wanatani (agroforestry) merupakan salah satu bentuk dari Perhutanan sosial. Wanatani tidak hanya terbatas untuk dikembangkan dalam kawasan hutan, tetapi juga dikembangkan di luar kawasan hutan. Penerapan konsep wanatani dalam kawasan hutan diarahkan untuk meningkatkan optimalisasi pemanfaatan lahan hutan, baik mengenai ruang tumbuh kawasan hutan maupun komoditinya melalui pendekatan peran serta dan peningkatan kesejahteraan masyarakat. Selain itu, prinsip pendekatan kesejahteraan masyarakat di sekitar hutan juga dapat ditempuh melalui penerapan dan pengembangan konsep wanatani di lahan milik masyarakat, agar pemanfaatan lahan milik dapat dilakukan seoptimal mungkin (Indriyanto 2008).

Fenomena pendekatan perhutanan sosial saat ini juga diterapkan oleh Koperasi Perumahan Wanabakti Nusantara (KPWN) dengan menanam Jati Unggul Nusantara (JUN) pada areal-areal masyarakat dengan menggunakan pola tanaman campuran atau kombinasi antara tanaman kehutanan dan tanaman pertanian agroforestry dengan sistim bagi hasil.

Jati Unggul Nusantara (JUN) merupakan suatu produk bibit tanaman jati baru, yang diproduksi oleh PT Setyamitra melalui induksi akar asal Jati Plus Perhutani (JPP).

Kombinasi Jati Unggul Nusantara (JUN) dengan pola bagi hasil serta pengaplikasian silvikultur yang intensif diduga akan menghasilkan tanaman Jati Unggul Nusantara (JUN) yang memiliki riap tumbuh lebih besar.

Namun demikian, sampai saat ini informasi tentang pengaruh tanaman tumpangsari terhadap pertumbuhan Jati Unggul Nusantara (JUN) belum diketahui, sehingga menjadi penting untuk dilakukan penelitian terkait dengan hal tersebut.

\section{Rumusan Masalah}

Apakah tanaman tumpangsari mempengaruhi pertumbuhan dan perkembangan Jati Unggul Nusantara (JUN).

\section{Tujuan Penelitian}

- Untuk mengetahui riap tinggi, diameter dan volume Jati Unggul Nusantara (JUN) umur lima tahun

- Untuk mengetahui hubungan diamater terhadap volume Jati Unggul Nusantara (JUN) umur lima tahun

- Untuk mengetahui pengaruh tanaman tumpangsari dan tanaman tanpa tumpangsari terhadap pertumbuhan Jati Unggul Nusantara (JUN) umur lima tahun

\section{Manfaat Penelitian}

Sebagai suatu informasi pengayaan tentang pola tanam Jati Unggul Nusantara (JUN).

\section{BAHAN DAN METODE}

\section{Waktu dan Tempat}

Penelitian ini dilakukan di Kebun Penelitian Cogreg Bogor, penelitian ini dilaksanakan selama satu bulan dari tanggal 15 Nopember sampai 13 Desember 2011. 


\section{Bahan dan Alat}

Bahan yang digunakan dalam penelitian ini adalah tanaman Jati Unggul Nusantara (JUN) dan tanaman Tumpangsari.

Alat - alat yang digunakan: Pita ukur $(150 \mathrm{~cm})$ untuk mengukur keliling, Galah/Paralon plastik $(9,5 \mathrm{~m})$ untuk mengukur tinggi, Buku ekspedisi dan alat tulis untuk mencatat data dari lapangan, Komputer untuk merekap dan mengolah data, Peta petak petani untuk mengetahui batas dan letak petak petani, Kamera digital untuk dokumentasi penelitian, Peta Pohon untuk memudahkan dalam pencaharian nomor sampel.

\section{Metode Pengumpulan Data}

Data yang diperoleh dalam penelitian ini berupa data primer dan data sekunder. Data primer merupakan data yang langsung diperoleh di lokasi penelitian, yaitu data yang didapat dengan cara pengamatan secara langsung di Kebun Percobaan Cogreg. Data Primer yang dibutuhkan dalam penelitian adalah :

a. Kelompok Tanaman Tumpangsari

Pengambilan data tanaman tumpangsari dilakukan dengan cara, wawancara langsung dengan petani yang menggarap lahan di Kebun Percobaan Cogreg. Tiga kelompok tersebut adalah 1). Kelompok tanaman giliran (ubi kayu, padi, jagung, kacang - panjang), 2). Kelompok tanaman tahunan (pepaya), dan 3). Tanpa tanaman tumpangsari

b. Tanaman Pokok JUN, meliputi : 1). Pertumbuhan tinggi $(\mathrm{T})$ dan diameter (D) dan perhitungan volume (V).

Data sekunder merupakan data pendukung atau penunjang dari data primer yang digunakan. Data sekunder diperoleh melalui studi pustaka berupa : Peta kerja, Data - data monografi desa, Jenis tanah, Curah hujan $3-5$ tahun $(\mathrm{mm} / \mathrm{thn}, \mathrm{mm} / \mathrm{hari})$, Pola penanaman dan perawatan JUN umur 1 tahun, Data - data petani, petak, jenis tanaman, tumpangsari.

\section{Prosedur Penelitian}

\section{Penentuan Petak Pengamatan}

Petak yang akan diamati terdiri dari 3 (tiga) petak yang masing-masing mewakili tanaman tumpangsari dan yang tidak memakai tanaman tumpang sari.

\section{Penentuan pohon sampling Jati Unggul Nusantara (JUN)}

Untuk pengambilan sampel pohon Jati Unggul Nusantara (JUN) dilakukan secara systematic sampling with random start dengan intensitas sampling (IS $=10 \%$ ), dari jumlah tanaman tiap petak.

\section{Analisa Data \\ Riap Rata - rata Tahunan}

Riap Rata - rata Tahunan ( Mean Annual Increament ) untuk diameter, tinggi dan volume menurut Marsono (1987) dalam Latifah (2006) dengan rumus :

$\begin{aligned} \text { MAI diameter } & =\frac{D_{b h}}{\text { umur }}(\mathrm{cm} / \text { tahun }) \\ \text { MAI tinggi } & =\frac{\text { tinggi }}{\text { umur }}(\mathrm{m} / \text { tahun }) \\ \text { MAI volume } & =\frac{\text { volume }}{\text { umur }}\left(\mathrm{m}^{3} / \text { tahun }\right)\end{aligned}$

Pola Hubungan Volume dengan Diameter

Pola hubungan antara volume dan diameter Jati Unggul Nusantara (JUN) umur lima tahun dapat dirumuskan dengan Power Regresi sebagai berikut :

$$
\boldsymbol{Y}=\boldsymbol{a} \cdot \boldsymbol{X}^{b}
$$

Keterangan :

$\mathrm{Y} \quad=$ Volume

$\mathrm{X}=$ Diameter

$\mathrm{a}$ dan $\mathrm{b}=$ koefisien regresi 
Bentuk persamaan power regresi menghasilkan persamaan linier sebagai berikut :

$\ln \mathrm{Y}=\ln \mathrm{a}+\mathrm{b} \ln \mathrm{X}$

$\mathrm{Y}=\mathrm{a}^{\prime}+\mathrm{b} . \mathrm{X} ; \mathrm{Y}=\ln \mathrm{V}, \mathrm{X}=\ln \mathrm{D}, \mathrm{a}^{\prime}=$ anti $\ln \mathrm{a}$

\section{General Linear Model - Multivariate}

Analisis General Linear ModelMultivariat merupakan analisis regresi dengan dua atau lebih variabel dependent dengan dua atau lebih variabel faktor atau variable - variabel lainnya. Variabel faktor membagi populasi ke dalam kelompok kelompok. Dengan prosedur General Linear Model mampu menguji pengaruh suatu variabel terhadap rata - rata variabel dependen pada berbagai kelompok.

\section{HASIL DAN PEMBAHASAN}

\section{Hasil}

\section{Riap Diameter Rata - rata Tahunan}

Dari hasil penelitian terhadap riap diameter rata - rata tahunan Jati Unggul Nusantara (JUN) pada umur 5 tahun dari berbagai perlakuan disajikan pada Tabel 1 .

Dari Tabel 1 hasil analisis terlihat bahwa riap diameter rata - rata tahunan (JUN) pada perlakuan tanpa tumpangsari (kontrol) mempunyai riap diameter terbesar nilai rata - rata $3,17 \mathrm{~cm} /$ tahun, dengan diameter minimum $9,90 \mathrm{~cm}$ dan maksimum $19,85 \mathrm{~cm}$.

\section{Riap Tinggi Rata - rata Tahunan JUN.}

Dari hasil penelitian terhadap riap tinggi rata - rata tahunan Jati Unggul Nusantara (JUN) pada umur 5 tahun dari berbagai perlakuan disajikan pada Tabel 2 .

Tabel 1. Riap Diameter Rata - rata Tahunan JUN Umur 5 Tahun

\begin{tabular}{llll}
\hline Variabel & $\begin{array}{c}\text { Riap Diameter Rata }- \\
\text { rata Tahunan } \\
(\mathrm{cm} / \text { tahun })\end{array}$ & $\begin{array}{c}\text { Diameter } \\
\text { minimum } \\
(\mathrm{cm})\end{array}$ & $\begin{array}{c}\text { Diameter } \\
\text { maksimum } \\
(\mathrm{cm})\end{array}$ \\
\hline Kontrol & 3,17 & 9,90 & 19,85 \\
TS Tahunan & 2,99 & 9,07 & 20,46 \\
TS Giliran & 2,80 & 9,55 & 21,00 \\
\hline
\end{tabular}

Tabel 2. Riap Tinggi Rata - rata Tahunan JUN Umur 5 Tahun

\begin{tabular}{llll}
\hline Variabel & $\begin{array}{c}\text { Riap Tinggi Rata } \\
\text { rata Tahunan } \\
\text { (m/tahun) }\end{array}$ & $\begin{array}{c}\text { Tinggi minimum } \\
(\mathrm{m})\end{array}$ & $\begin{array}{c}\text { Tinggi maksimum } \\
(\mathrm{m})\end{array}$ \\
\hline Kontrol & 2,66 & 10,75 & 16,10 \\
TS Tahunan & 2,39 & 5,70 & 15,70 \\
TS Giliran & 2,44 & 9,00 & 13,65 \\
\hline
\end{tabular}


Dari Tabel 2 hasil analisis secara deskripsi terlihat bahwa riap tinggi rata rata tahunan (JUN) pada perlakuan tanpa tumpangsari (kontrol) mempunyai riap tinggi paling besar nilai rata - rata 2,66 $\mathrm{m} /$ tahun, dengan tinggi minimum $10,75 \mathrm{~m}$ dan maksimum $16,10 \mathrm{~m}$.

\section{Riap Volume Rata - rata Tahunan JUN.}

Dari hasil penelitian terhadap riap volume rata - rata tahunan Jati Unggul Nusantara (JUN) pada umur lima tahun dari berbagai perlakuan disajikan pada Tabel 3.

Dari Tabel 3 hasil analisis terlihat bahwa riap volume rata - rata tahunan (JUN) pada perlakuan tanpa tumpangsari (kontrol) mempunyai riap volume terbesar nilai rata - rata $0,039 \mathrm{~m} 3 /$ tahun, dengan volume minimum $0,062 \mathrm{~m} 3$ dan maksimum $0,337 \mathrm{~m} 3$.

Kondisi tersebut diduga bahwa tanaman tanpa tumpangsari tidak mengalami gangguan dalam mendapatkan unsur hara dalam pertumbuhan dan perkembangannya. Sehingga dengan tidak adanya gangguan tersebut maka baik tinggi dan diameter tanaman dapat berkembang secara normal.

\section{Pola Hubungan Volume dengan Diameter}

Untuk mengetahui hubungan volume dan diameter JUN dilakukan analisis regresi dan uji korelasi. Hasil perhitungan regresi dan korelasi diperoleh persamaan sebagai berikut :

$$
Y=1,063 \times 10^{-4} \cdot X^{2,343}
$$

Keterangan :

$\mathrm{Y} \quad=$ Volume $\left(\mathrm{m}^{3}\right)$

$\mathrm{X}=\operatorname{Diameter}(\mathrm{cm})$

$\mathrm{a}$ dan $\mathrm{b}=$ koefisien regresi

Dengan besar nilai $r=0,952$, atau terjadi hubungan yang sangat erat antara volume dengan diameter.

Dari hasil persamaan tersebut dapat diartikan bahwa setiap penambahan diameter $1 \mathrm{~cm}$, maka volume juga akan bertambah besar secara eksponensial.

\section{General Linear Model-Multivariate}

Analisis General Linear Model Multivariate merupakan analisis regresi dengan dua atau lebih variabel dependent dengan dua atau lebih variabel faktor atau variable - variabel lainnya.

Uji tes Pillai's Trace, Wilk's Lambda, Hotelling's Trace dan tes Roy's Largest Root seluruhnya mempunyai nilai signifikan $<\alpha(0,05)$ sehingga dapat dikatakan bahwa pola pengelolaan tanaman berpengaruh terhadap variabel diameter, tinggi dan volume (variabel dependen) Jati Unggul Nusantara(JUN).

Namun dengan uji hipotetis ketiga jenis pengelolaan tanaman dengan dan tanpa tumpangsari tidak berpengaruh terhadap diameter, tetapi berpengaruh terhadap tinggi dan volume tanaman Jati Unggul Nusantara (JUN).

Hasil dari estimasi parameter terhadap diameter, pada pola pengelolaan tanaman tahunan mempunyai diameter lebih rendah $0,235 \mathrm{~cm}$ dibandingkan dengan pola.

Tabel 3. Riap Volume Rata - rata Tahunan JUN Umur Lima Tahun

\begin{tabular}{llll}
\hline Variabel & $\begin{array}{c}\text { Riap Volume Rata }- \\
\text { rata Tahunan } \\
\left(\mathrm{m}^{3} / \text { tahun }\right)\end{array}$ & $\begin{array}{c}\text { Volume minimum } \\
\left(\mathrm{m}^{3}\right)\end{array}$ & $\begin{array}{c}\text { Volume } \\
\text { maksimum } \\
\left(\mathrm{m}^{3}\right)\end{array}$ \\
\hline Kontrol & 0,039 & 0,062 & 0,337 \\
TS Tahunan & 0,032 & 0,035 & 0,295 \\
TS Giliran & 0,028 & 0,045 & 0,388 \\
\hline
\end{tabular}




\section{KESIMPULAN DAN SARAN}

\section{Kesimpulan}

Riap rata - rata tahunan dipengaruhi oleh pola pengelolaan tumpangsari tahunan maupun tumpangsari giliran.

Riap rata tahunan pada pola pengelolaan tanpa tumpangsari (kontrol) mempunyai riap rata - rata paling besar dibanding kedua pengelolaan untuk diameter sebesar $3,17 \mathrm{~cm} /$ tahun, untuk tinggi sebesar 2,66 m/tahun dan riap rata rata tahunan untuk volume sebesar 0,039 $\mathrm{m}^{3} /$ tahun.

Power Regresi dari hasil penelitian adalah $\mathrm{Y}=1,063 \times 10^{-4} \cdot \mathrm{X}^{2,343}$

Terjadi hubungan yang sangat erat antara volume dengan diameter dengan nilai R sebesar 0,952 .

Hasil analisis dengan multivariat variabel pola pengelolaan tanaman (variabel independen) berpengaruh terhadap variabel diameter, tinggi dan volume (variabel dependen) Jati Unggul Nusantara(JUN).

Hasil dari analisis estimasi parameter terhadap diameter, pada pola pengelolaan tanaman tahunan mempunyai diameter lebih rendah $0,235 \mathrm{~cm}$ dibandingkan dengan pola pengelolaan tanaman giliran.

\section{Saran}

Dalam rangka meningkatkan produksi, pola pengelolaan penanaman tanpa tumpangsari dapat digunakan sebagai pola pada penanaman Jati Unggul Nusantara (JUN).

Dalam rangka usaha bagi hasil dalam penanaman Jati Unggul Nusantara (JUN) dengan masyarakat, apabila dengan pola tumpangsari disarankan dengan pola pengelolaan tanaman tumpangsari tahunan.

\section{DAFTAR PUSTAKA}

Baga K. M., 1994. Bertanam Pepaya : PT Penebar Swadaya, Anggota IKAPI. Jakarta.
Darmawan J, J. Baharsjah, 1983. Dasar Dasar Ilmu Fisiologi Tanaman : PT Suryandaru.

Hardjowigeno, S., 1987. Ilmu Tanah : Mediyatama Sarana Perkasa. Jakarta.

Hairiah K, S. R. Utami, D. Suprayogo, Widianto, Sitompul SM, Sunaryo, B. Lusiana, R. Mulia, M. Van Noordwijk dan G. Cadisch, 2000. Agroforestri pada tanah masam di daerah tropika basah : Pengelolaan interaksi antara pohon-tanah-tanaman semusim. ISBN 979-95537-5-X. 41 p.

Haryanto E, T. Suhartini, E. Rahayu, 1999. Budidaya Kacang Panjang, Edisi VI : PT Penebar Swadaya, Anggota IKAPI. Jakarta.

Indriyanto, 2008. Pengantar Budi Daya Hutan. Jakarta : PT Bumi Aksara.

Lakitan, B., 2000. Dasar-dasar Fisiologi Tumbuhan : PT Raja Grafindo. Jakarta.

Latifah, S., 2004, Pertumbuhan dan Hasil Tegakan Eucalyprus grandis di Hutan Tanaman Industri. @ 2004. Digitized by USU digital Library.

Mahfudz, 2004. Peranan Benih Berkualitas Dalam Mendukung Pengembangan Hutan Rakyat Jati. Ekspose Hasil - hasil Penelitian badan Penelitian dan Pengembangan Kehutanan.

Marjanin, M., Hadmadi,1980. Ilmu Hayat Dalam Pertanian, Jilid. I : CV YASAGUNA. Jakarta.

Manual Kehutanan, 1992. Jakarta : Departemen Kehutanan Republik Indonesia.

Marom, O, 2008. Evaluasi Tanaman Jati (Tectona grandis Linn.f) Asal 
Kultur Jaringan Umur 7 Tahun dengan Perlakuan Ukuran Lubang Tanam dan Pemupukan Awal di Hutan Penelitian Parung Panjang. Bogor. Skripsi.

Martawijaya, A, K. Iding, K. Kosasih dan A. P. Soewanda, 1981. Jati (Tectona grandis Linn. F) dalam Atlas Kayu Indonesia Jilid I. Badan Penelitian dan Pengembangan Kehutanan. Jakarta.

Nasir, M., 1988. Metode Penelitian : Ghalia Indonesia. Jakarta.

Nurhasybi, 2003. Jati (Tectona grandis Linn. f). Atlas Benih Tanaman Hutan Indonesia. Jilid I. Publikasi Khusus. Vol 2 No. 3. Balai Teknologi Perbenihan. Bogor.

Pandit, I. K. N. Ramdan H., 2002. Anatomi Kayu : Pengantar Sifat Kayu Sebagai Bahan Baku : (YPPK) Kampus Fakultas Kehutanan IPB. Bogor.

Sadharjo, 2001. Pusat Jati dan Bibit Unggul Jati Plus Perhutani. Duta Rimba. No.258/XXV-Desember 2001. Perum Perhutani. Jakarta. P22-23.

Santosa, 2004 Statistik Multivariat. Elex Media Komputindo, Jakarta.

Sarief, E. S., 1985. Kesuburan Dan Pemupukan Tanaman Pertanian. Pustaka Buana.Bandung.

Simon, H, 1993. Metoda Inventore Hutan. Aditya Media Yogyakarta.
Soeroso H \& D. P. Soetadjo, 2008. Usahatani Jati Unggul Pola Bagi Hasil 5 Tahun Panen, cetakan IV. Jakarta.

Sopyan, A., I. Muslimin, Triwilaida, Bastoni, P. Andriani, dan Islam, S., 2006. Pertumbuhan Tanaman Jati pada berbagai Daerah di Sumatera Selatan. Proseding Seminar Hasil - hasil Penelitian "Optimasi Peran Iptek dalam Mendukung Peningkatan Produktifitas Hutan dan Lahan. Jambi, 22 Desember 2006. Badan dan Penelitian dan Pengembangan Kehutanan.

Suprapto, HS., 1992. Bertanam Jagung : Penebar Swadaya. Jakarta.

Supriono, B., 1998. Tinjauan Permasalahan Neraca Hara Hutan Produksi dan Alternatif Pemecahannya. Bogor. Skripsi.

Suryadi, 2003. Perbanyakan Tanaman Jati (Tectona grandis Linn f) Melalui Teknik Kultur Jaringan. Bogor. Praktek Kerja Lapang (PKL).

Trihendardi, (2011). Langkah mudah melakukan analisis statistik menggunakan SPSS 19, CV. Andi Offset, Yogyakarta.

Walpole, R. E., 1992. Pengantar Statistika Edisi III. Jakarta : PT. Gramedia Pustaka Utama.

Winarto, B., 2006. Kamus Rimbawan. Jakarta : Inter Aksara Prima. 